\title{
PROGRESSO DA FERRUGEM E DA CERCOSPORIOSE EM CAFEEIRO (Coffea arabica L.) COM DIFERENTES ÉPOCAS DE INÍCIO E PARCELAMENTOS DA FERTIRRIGAÇÃO ${ }^{1}$
}

\author{
VIVIANE TALAMINI \\ EDSON AMPÉLIO POZZA ${ }^{3}$ \\ PAULO ESTEVÃO DE SOUZA ${ }^{3}$ \\ ANTONIO MARCIANO DA SILVA ${ }^{4}$
}

\begin{abstract}
RESUMO - Avaliações da incidência da ferrugem (Hemileia vastatrix Berk. \& Br.) e da cercosporiose (Cercospora coffeicola Berk. \& Cooke) foram realizadas em experimento com a cultura do café cultivar ' $\mathrm{Ca}$ tuai', com 12 anos de cultivo. Os objetivos foram avaliar o efeito da irrigação e da fertirrigação na incidência da ferrugem e da cercosporiose, analisar a curva de progresso dessas doenças e sua correlação com as variáveis climáticas. $\mathrm{O}$ delineamento experimental foi o de blocos ao acaso, com 4 tratamentos de diferentes parcelamentos de adubação (1: 12 aplicações manuais, 2: 12 aplicações via fertirrigação, 3: 24 aplicações fertirrigado, 4: 36 aplicações fertirrigado). As parcelas foram divididas em 3 subparcelas com diferentes épocas de início de irrigação (subparcelas $A: 1^{\circ}$ de junho, B: 15 de julho, C: $1^{\circ}$ de setembro) e 2 tratamentos adicionais (testemunhas): tratamento adicional 1- fertirrigação parcelada em 4 vezes e não irrigado; tratamento adicional 2- adu-
\end{abstract}

\begin{abstract}
bação convencional, não irrigado. Observou-se a incidência de ambas as doenças em 6 folhas por planta a cada 14 dias durante o período de 21 de março de 1998 a 6 de fevereiro de 1999. Calculou-se a área abaixo da curva de progresso da doença (AACPD), procedendo-se à análise de variância e teste de Tukey a 5\%. Para a ferrugem do cafeeiro, nenhum tratamento foi significativo, e as incidências máximas foram nos meses de julho a setembro. Houve correlação significativa entre todos os tratamentos e as variáveis climáticas, com exceção da temperatura máxima. Para a cercosporiose, observou-se nas parcelas, maior AACPD para os tratamentos 2 e 4 . $\mathrm{O}$ tratamento adicional 1 apresentou maior AACPD, seguida pelo tratamento adicional 2 . De acordo com as curvas de progresso da doença, a incidência máxima foi entre maio a setembro. Houve correlação significativa da incidência da cercosporiose com as variáveis climáticas na maioria dos tratamentos.
\end{abstract}

TERMOS PARA INDEXAÇÃO: Café, fertirrigação, irrigação, manejo, epidemiologia, Hemileia vastatrix, Cercospora coffeicola, Coffea arabica.

\section{PROGRESS OF COFFEE RUST AND BROWN EYE SPOT WITH DIFFERENTS PERIODS AT INITIAL IRRIGATION AND FERTIRRIGATION TIME}

\begin{abstract}
Evaluations of incidence of rust (Hemileia vastatrix Berk. \& Br.) and brown eye spot (Cercospora coffeicola Berk. \& Cooke) took place at intervals of 14 days, observing 6 leaves per plant during the period from March 21, 1998 to February 6, 1999 in a 'Catuai' culture. The objective was to evaluate the effect of irrigation and fertirrigation on the incidence of rust and in 12 year coffee plants and analyze the
\end{abstract}

progress curve of these diseases and their correlation to climatic variables. The experimental design was the one of randomized blocks with four treatments of different fertilizer splitting (1: 12 hand applications, 2:12 applications via fertirrigation, 3: 24 fertirrigated applications, 4: 36 fertirrigated applications). The plots were divided in 3 subplots that received treatments in different periods at initial

\footnotetext{
1. Parte da dissertação apresentada à UNIVERSIDADE FEDERAL DE LAVRAS/UFLA, Caixa Postal 37 - 37200-000 Lavras, MG, pelo primeiro autor, para obtenção do título de Mestre em Fitopatologia, na área de Epidemiologia.

2. Doutoranda do Departamento de Fitopatologia/UFLA.

3. Professores do Departamento de Fitopatologia/UFLA.

4. Professor do Departamento de Engenharia/UFLA.
} 
irrigation (subplots A: June 1, B: July 15, C: September 1), and 2 checks (additional treats 1: fertilized 4 times and not irrigated, additional treats 2 : conventional fertilizer and not irrigated). The area under disease progress curve (AUDPC) was calculated and submitted to variance analysis and Tukey's test at 5\% probability. For the coffee rust, no treatment was significant. Curve progress showed maximum incidences in the months of July and September. There was a significant correlation at $1 \%$ probability among all the treatments and climatic variables, with the exception of the maximum temperature. For brown eye spot, the treatments attributed to the plots and to the subplots were significant at $1 \%$ of probability. However, the interaction between the two was nonsignificant. Greater AUDPC in splitting fertilizer 2 and 4 was observed. In the subplots, greater AUDPC in check $\mathrm{E}$ following for $\mathrm{D}$ was observed. Curve progress showed maximum incidences from May to July. There was a significant correlation of brown eye spot incidence in the majority of the treatments in relation to climatic variables.

INDEX TERMS: Coffee, fertirrigation, irrigation, management, epidemiology, Hemileia vastatrix, Cercospora coffeicola, Coffea arabica.

\section{INTRODUÇÃO}

A cultura do café Coffea arabica é suscetível a inúmeras doenças da parte aérea, destacando-se, entre elas, em função dos danos, a ferrugem (Hemileia vastatrix Berk. \& Br.) e a cercosporiose (Cercospora coffeicola Berk. e Cooke). A maior ou menor intensidade dessas doenças está associada ao ambiente, ao patógeno, ao hospedeiro e ao manejo da cultura (Mansk, 1990; Zambolim et al, 1997).

Em se tratando do manejo da cultura, nas regiões onde as chuvas são escassas ou mal distribuídas, a irrigação assume fundamental importância para o cultivo do cafeeiro. A irrigação por si só não determinará o aumento da incidência ou da severidade das doenças, mas sim o microclima criado pelo sistema, o qual interage com o tipo de solo, quantidade de nutrientes do solo, fatores relacionados ao manejo da cultura, variedade plantada, seu porte, espaçamento, entre outros (Ribeiro do Vale \& Zambolim, 1996). Em certos casos, a irrigação pode conferir ao hospedeiro maior resistência em razão do aumento do seu vigor (Campbell \& Madden, 1990). No entanto, o microclima proporcionado pode favorecer o aumento na taxa de progresso de epidemias (Rotem \& Palti, 1969).

Quando utiliza-se o sistema de irrigação de forma localizada, como o gotejamento, no caso de patógenos de solo, o teor de umidade do solo afeta simultaneamente a suscetibilidade do hospedeiro e a virulência do patógeno. Para as doenças foliares, os efeitos da umidade no solo são limitados ao hospedeiro pela emissão de novas brotações e órgãos suscetíveis, pela extensão do período de crescimento para épocas nas quais outros fatores do ambiente, além da umidade, deixam o hospedeiro suscetível e pelo aumento da turgidez dos órgãos do hospedeiro (Rotem \& Palti, 1969).
Deficiências e desequilíbrios nutricionais também afetam a intensidade das doenças nos cafezais. Algumas vezes, as deficiências nutricionais podem ser provocadas por falta de umidade no solo (FernandezBorrero \& Lopez-Duque, 1971; Godoy et al., 1997; Santos et al., 1986; Siddiqi, 1970). O sistema de irrigação por gotejamento permite que, além da água, sejam enviados nutrientes às plantas por meio da fertirrigação. Em regiões de montanha, esse sistema pode contribuir para minimizar os custos com mão-de-obra, por reduzir ou eliminar a adubação manual. Essa prática tem sido bem aceita pelos produtores graças ao aumento substancial da produtividade, tanto em regiões com déficit hídrico para a cultura, quanto em regiões tradicionais, como o sul de Minas Gerais, por proporcionar a aplicação de fertilizantes via água de irrigação. Entretanto, são raros os trabalhos que avaliam os efeitos da irrigação e/ou fertirrigação no ambiente e no comportamento das doenças, que, em virtude de modificações decorrentes dessa prática, podem apresentar a taxa de progresso alteradas.

Com o presente trabalho, objetivou-se avaliar as curvas de progresso da incidência da ferrugem e da cercosporiose em plantas de café irrigadas e fertirrigadas por gotejamento, e analisar a correlação entre a incidência das doenças e as variáveis climáticas.

\section{MATERIAL E MÉTODOS}

As avaliações foram feitas em experimento localizado na área da Fazenda Muquem da FAEPE/UFLA, localizada na altitude de $918 \mathrm{~m}$, latitude sul de $21^{\circ} 14^{\prime}$, longitude oeste de $45^{\circ} 00^{\prime}$ e Latossolo Vermelho-Escuro. Utilizou-se a cultivar Catuai, suscetível à ferrugem e à cercosporiose, no espaçamento $3,5 \times 1 \mathrm{~m}$, com 12 anos de cultivo. 
O delineamento experimental foi o de parcelas subdivididas com quatro repetições. Cada parcela constituiu-se de uma fileira de 40 plantas divididas em cinco subparcelas formadas por oito plantas cada uma. Nas parcelas, foram dispostos quatro tratamentos:

i- adubação manual em 12 parcelamentos de nitrogênio, fósforo e potássio;

ii- adubação via água de irrigação em 12 parcelamentos de nitrogênio, fósforo e potássio (fertirrigação a cada 15 dias);

iii- adubação via água de irrigação em 24 parcelamentos de nitrogênio, fósforo e potássio (fertirrigação a cada 10 dias);

iv- adubação via água de irrigação em 36 parcelamentos de nitrogênio, fósforo e potássio (fertirrigação semanal).

Nas subparcelas, foram testados três diferentes épocas de início da irrigação, que foram:

Subparcela A - irrigação a partir de $1^{\circ}$ de junho até início de outubro;

Subparcela B - irrigação a partir de 15 de julho até início de outubro;

Subparcela $\mathrm{C}$ - irrigação a partir de $1^{\circ}$ de setembro até início de outubro.

Também foram avaliados dois tratamentos adicionais (testemunhas, sem irrigação)

1- Não irrigado, com adubo da fertirrigação parcelado em quatro vezes;

2- Não irrigado com adubação convencional.

A lâmina aplicada foi definida em função da evapotranspiração acumulada no período entre as irrigações, em número de três por semana. A evapotranspiração da cultura foi estimada multiplicando-se a evaporação do tanque classe A (ECA) pelo "fator tanque" (Kp), tabelado em função da umidade relativa e vento e pelo coeficiente de cultura $(\mathrm{Kc})$ específico para o café.

Para a safra 1997/1998, foi utilizado o adubo de alta solubilidade Kristalon Azul Claro, para fertirrigação. Com $20 \%$ de N, $5 \%$ de $\mathrm{P}_{2} \mathrm{O}_{5}, 10 \%$ de $\mathrm{K}_{2} \mathrm{O}, 2 \%$ de $\mathrm{MgO}$, definiu-se a quantidade do adubo segundo análise química do solo baseada na $5^{\mathrm{a}}$ Aproximação. A quantidade utilizada foi de $450 \mathrm{~g}$ do adubo por planta, dividida de acordo com o número de parcelamentos. O tratamento adicional 1 também recebeu $450 \mathrm{~g}$ do mesmo adubo por planta, porém divididos em 4 vezes. O tratamento adicional 2 não foi irrigado e recebeu adubação convencional, utilizando-se $300 \mathrm{~g}$ por planta da formulação: $20 \%$ de N, $5 \%$ de $\mathrm{P}_{2} \mathrm{O}_{2}$ e $20 \%$ de $\mathrm{KCl}$, parcelados em 3 vezes e distribuídos manualmente. Esse tratamento ainda recebeu três toneladas de calcário dolomítico por hectare.
Para a safra 1998/1999, foram utilizadas duas formulações de adubo: a utilizada em 97/98 e o Nitrato de cálcio com $15,5 \%$ de $\mathrm{N}$ e $5 \%$ de $\mathrm{CaO}$. O total de fertilizantes utilizado foi de $635 \mathrm{~g}$ por planta (391g de potássio e $244 \mathrm{~g}$ de nitrogênio). A quantidade total do adubo foi dividida de acordo com o número de parcelamentos.

Com a finalidade de monitorar a incidência das doenças, realizaram-se avaliações em intervalos de 14 dias, entre 21 de março de 1998 e 6 de fevereiro de 1999. Foram coletadas 6 folhas por planta, sendo 3 folhas de cada lado, no terço médio, entre o terceiro e quarto par de folhas, ao acaso, correspondendo a 48 folhas por subparcela e 240 folhas por parcela.

Após a obtenção dos dados, foram plotadas as curvas de progresso da doença para a incidência. A partir das curvas de progresso, calculou-se a área abaixo da curva de progresso da doença (AACPD) por meio da equação proposta por Campbell \& Madden (1990), sendo realizadas as análises de variância e as médias comparadas pelo teste de Tukey a 5\% de probabilidade.

Foram coletados os dados climáticos diários da Estação Climatológica localizada no campus da Universidade Federal de Lavras, calculando-se a média dos últimos 14 dias anteriores às avaliações da incidência das doenças. Foram obtidos os dados de precipitação $(\mathrm{mm})$, umidade relativa do ar (\%), temperatura máxima, mínima, e média $\left({ }^{\circ} \mathrm{C}\right)$ para o período de março de 1998 a fevereiro de 1999. Esses dados foram correlacionados, pelo método de PEARSON, com a incidência das doenças em cada tratamento.

\section{RESULTADOS E DISCUSSÃO}

\section{Ferrugem do cafeeiro}

Os diferentes parcelamentos da adubação não influenciaram significativamente o progresso da ferrugem. Os diferentes parcelamentos de adubação também não influenciaram a incidência da ferrugem em plantas de café com até dois anos. A quantidade total de nutrientes aplicada em todos os tratamentos foi a mesma. Os diferentes parcelamentos de adubação, embora em épocas diferentes, podem ter suprido as necessidades das plantas. As informações disponíveis na literatura sobre o efeito da nutrição mineral do cafeeiro no progresso da ferrugem são escassas; no entanto, Carvalho (1991) observou maior progresso da doença em baixos níveis de potássio.

Para as condições de Lavras, a irrigação por gotejamento não alterou o progresso da doença ao longo do tempo, em relação às testemunhas não irrigadas. $\mathrm{O}$ 
sistema de irrigação por gotejamento distribui a água de forma localizada, portanto, não provoca o molhamento foliar e não favorece a disseminação e a germinação dos uredosporos de Hemileia vastatrix. Carvalho (1998) trabalhou com avaliações de incidência da ferrugem em cafeeiro irrigado por diferentes sistemas na cidade de Araguari no Triângulo Mineiro e observou menor incidência da ferrugem no gotejamento. $\mathrm{O}$ mesmo autor observou, ainda, na área irrigada com pivô central, vários picos da doença, ou seja, a ferrugem passou a apresentar comportamento cíclico, provavelmente decorrente do maior período de molhamento foliar e das modificações no padrão vegetativo das plantas por causa desse sistema de irrigação.

Independentemente do tratamento, foram observadas maiores incidências nos meses de julho a setembro, e a partir daí, a taxa de progresso tornou-se negativa. Em Lavras, no período de março a maio de 1998, ocorreu precipitação acumulada de $232 \mathrm{~mm}$. Esse fato pode ter favorecido a disseminação e a infecção, em consequiência da maior taxa de progresso da doença a partir do mês de junho, atingindo pontos de máximo nos meses de julho a outubro. A partir daí, houve um ponto de inflexão da curva de progresso da doença (Figura 1A, B e C). Chalfoun \& Zambolim (1985) observaram condição semelhante no ano agrícola de 1982 a 1983 , quando ocorreu atraso no início da epidemia da ferrugem devido a ocorrência de chuvas intensas durante os meses de dezembro a janeiro, promovendo a lavagem do inóculo da superfície foliar . Isso pode ter desfavorecido a doença, fazendo com que a ferrugem progredisse apenas a partir de março. Em seguida, a ocorrência de um inverno atípico (chuvas freqüentes e temperaturas elevadas) condicionou a maior incidência da ferrugem, atingindo ponto máximo em setembro, diferindo completamente do padrão normal do comportamento da doença.

No presente trabalho verificou-se a máxima incidência da doença por volta dos meses de julho a setembro; no entanto, Silva-Acuña et al. (1998), observando a sazonalidade da ferrugem na cidade de Patrocínio-MG, nos anos agrícolas de 1992 a 1994, verificaram, a partir de janeiro, o aumento gradativo da incidência, atingindo o ponto de máximo entre maio e junho. Kushalappa \& Chaves (1980) encontraram, em Viçosa-MG, alta incidência da ferrugem de janeiro a março. Souza (1980), monitorando a incidência da ferrugem, observou pontos de máxima incidência nos meses de maio a julho na cidade de Alfenas-MG. Akutsu (1981), estudando a curva de progresso da doença em Ponte Nova-MG, verificou incidência máxima nos meses de março a maio. Obser- vou-se, assim, grande variação com relação aos períodos de máxima incidência da doença, tanto de um ano para outro, quanto de uma região para outra. Assim sendo, consolida-se a idéia de Chalfoun (1997), na qual o deslocamento da curva está condicionada às variações climáticas de cada ano agrícola e local de produção.

No teste de correlação da doença com as variáveis climáticas, foram obtidas correlações negativas em todos os casos, com exceção da temperatura máxima (Tabela 2). Assim, conforme a temperatura mínima e média, precipitação e umidade relativa do ar diminuem, a incidência da doença aumenta. As correlações estão de acordo com as observações dos gráficos das variáveis climáticas (Figura 1). Os pontos de máxima incidência de ferrugem ocorreram nos pontos de inflexão das curvas das variáveis climáticas.

\section{Cercosporiose do cafeeiro}

A aplicação em 12 parcelamentos de adubação, distribuídos manualmente, e 24 parcelamentos, via água de irrigação, apresentaram menores áreas abaixo da curva de progresso da doença para a incidência da cercosporiose (Tabela 3).

Nas condições deste experimento, em lavoura com 12 anos de cultivo, a dose do adubo foi a mesma em todos os tratamentos, diferindo o número de aplicações. Nesse caso, a diferença detectada na AACPD pode ter sido devida à melhor distribuição e combinação dos nutrientes disponíveis às plantas, de acordo com as suas necessidades e no momento adequado, proporcionando menor incidência da cercosporiose. Portanto, não basta simplesmente definir a dose de adubo a ser aplicada nos cafezais - o número de aplicações e o intervalo de tempo podem alterar esse patossistema. No Brasil, a cercosporiose é responsável pela menor produtividade em lavouras mal conduzidas, onde há deficiência e falta de equilíbrio dos nutrientes. Nessas condições, pode ocorrer estresse nutricional e, conseqüentemente, aumento na intensidade da doença (Chalfoun, 1997; Zambolim et al., 1997; Carvalho \& Chalfoun, 1998). Desequilíbrios nutricionais em relação aos teores de nitrogênio e potássio levaram à maior intensidade da cercosporiose (AlexandrePozza, 1999). 
A

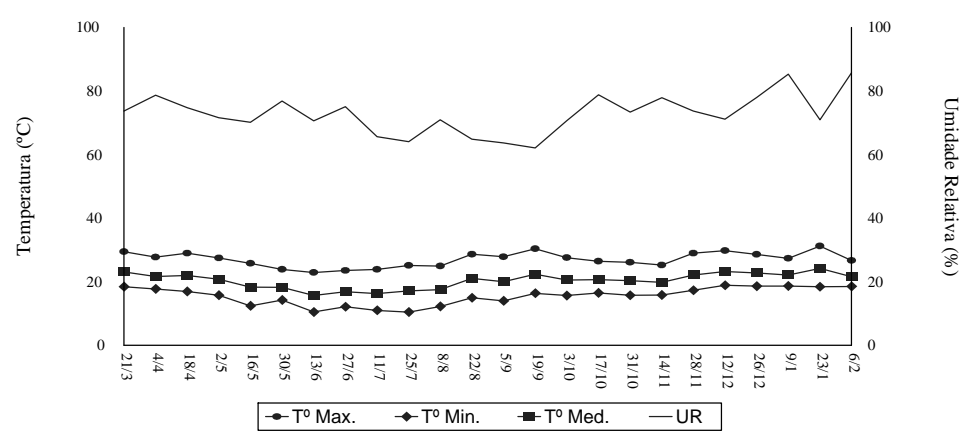

B

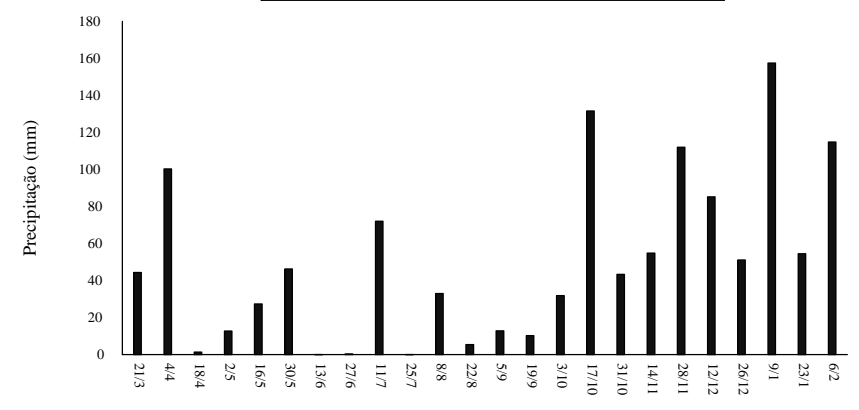

C

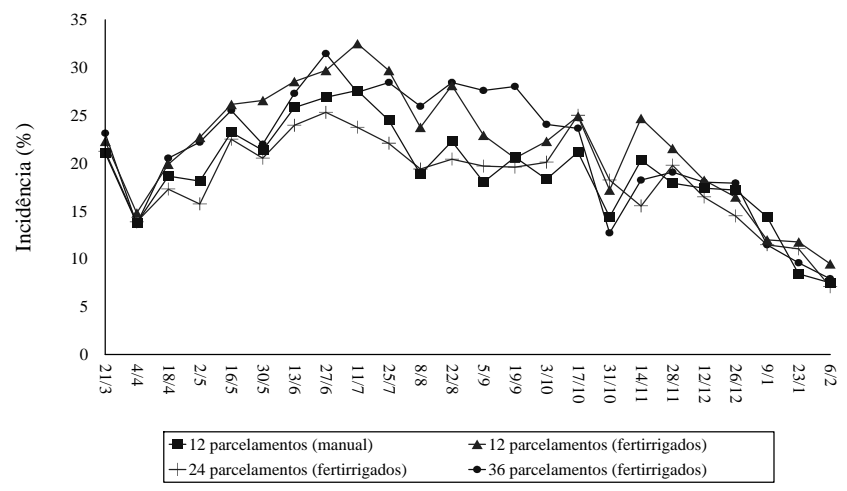

D

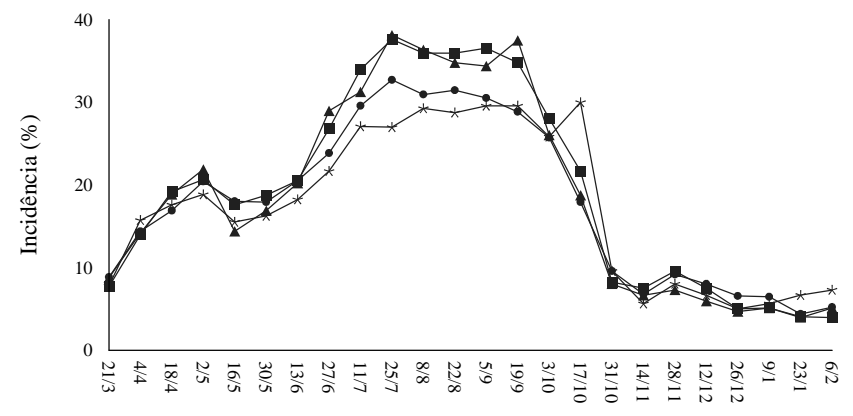

$\bullet-12$ parcelamentos adubação manual -12 parcelamentos (fertirrigados) * 24 parcelamentos (fertirrigados) $\$ 36$ parcelamentos (fertirrigados)

FIGURA 1 - Comportamento das variáveis climáticas (A, B) e progresso da incidência da ferrugem do cafeeiro (C) e da cercosporiose (D) em diferentes parcelamentos de adubação de 21 de março de 1998 a 6 de fevereiro de 1999. 
TABELA 2 - Teste de correlação dos dados climáticos de temperatura máxima, mínima e média, precipitação e umidade relativa do ar com a incidência da ferrugem nos diferente parcelamentos de adubação.

\begin{tabular}{lccccc}
\hline $\begin{array}{c}\text { Número } \\
\text { parcelamentos }\end{array}$ & $\begin{array}{c}\text { Temperatura } \\
\text { máxima }\left({ }^{\circ} \mathbf{C}\right)\end{array}$ & $\begin{array}{c}\text { Temperatura } \\
\text { mínima }\left({ }^{\circ} \mathbf{C}\right)\end{array}$ & $\begin{array}{c}\text { Temperatura } \\
\text { média }\left({ }^{\circ} \mathbf{C}\right)\end{array}$ & $\begin{array}{c}\text { Precipitação } \\
(\mathbf{m m})\end{array}$ & $\begin{array}{c}\text { Umidade } \\
\text { lativa }(\%)\end{array}$ \\
\hline 12 (manual) & $-0,33 \mathrm{NS}$ & $-0,74 * *$ & $-0,60^{* *}$ & $-0,59 * *$ & $-0,73^{* * *}$ \\
12 (fertirrigado) & $-0,29 \mathrm{NS}$ & $-0,71 * *$ & $-0,57 * *$ & $-0,56 * *$ & $-0,73 * *$ \\
24 (fertirrigado) & $-0,26 \mathrm{NS}$ & $-0,67 * *$ & $-0,53 * *$ & $-0,54 * *$ & $-0,70^{* *}$ \\
36 (fertirrigado) & $-0,27 \mathrm{NS}$ & $-0,69 * *$ & $-0,55^{* *}$ & $-0,59 * *$ & $-0,72^{* *}$ \\
\hline
\end{tabular}

** Significativo $\mathbf{P}(<0,01)$

NS - Não-significativo

TABELA 3 - Valores médios da área abaixo da curva de progresso da doença (AACPD) para incidência da cercosporiose do cafeeiro em quatro tratamentos.

\begin{tabular}{lc}
\hline \multicolumn{1}{c}{ Tratamentos } & AACPD* \\
\hline 1: 12 parcelamentos (manual) & $6204,7 \mathrm{a}$ \\
2: 12 parcelamentos (fertirrigação) & $7132,0 \mathrm{~b}$ \\
3: 24 parcelamentos (fertirrigação) & $6029,0 \mathrm{a}$ \\
4: 36 parcelamentos (fertirrigação) & $6967,1 \mathrm{~b}$ \\
\hline
\end{tabular}

*Médias seguidas pela mesma letra não diferem significativamente entre si pelo teste de Tukey a $5 \%$ de probabilidade.

Os tratamentos irrigados (subparcelas A, B, e C) apresentaram menor AACPD e não diferiram estatisticamente, seguidos pela testemunha adubada 4 vezes e não irrigada (tratamento adicional 1). O tratamento adicional 2, com o manejo convencional e não irrigado, apresentou maior AACPD (Tabela 4).

A testemunha adubada em quatro parcelamentos (tratamento adicional 1) recebeu a mesma dose e o mesmo adubo em relação às demais parcelas, e o mais importante, não recebeu lâmina de irrigação. Nesse ponto, a deficiência hídrica influenciou a maior incidência da cercosporiose, por impedir a absorção adequada de nutrientes pelas plantas. A testemunha com adubação convencional também não recebeu lâmina de irrigação e apresentou maior AACPD entre todas as subparcelas. A diferente formulação e quantidade do adubo aplicado no solo e a falta de água podem ter contribuído para o maior progresso da doença nesse caso.
TABELA 4 - Valores médios da área abaixo da curva de progresso da doença (AACPD) para incidência da cercosporiose do cafeeiro em cinco subparcelas.

\begin{tabular}{ll}
\hline \multicolumn{1}{c}{ Subparcelas } & \multicolumn{1}{c}{ AACPD* $^{*}$} \\
\hline A = irrigação de $1^{\circ}$ de junho a outubro & $5372,0 \mathrm{a}$ \\
B= irrigação de 15 de julho a outubro & $4795,9 \mathrm{a}$ \\
C= irrigação de $1^{\circ}$ de setembro a outubro & $4984,6 \mathrm{a}$ \\
D= não irrigada (4 parcelamentos) & $7888,7 \quad$ b \\
E= não irrigada (manejo convencional) & $9874,7 \quad \mathrm{c}$ \\
\hline
\end{tabular}

*Médias seguidas pela mesma letra não diferem significativamente entre si pelo teste de Tukey a $5 \%$ de probabilidade.

Vários autores afirmam ser a deficiência hídrica, associada à má absorção de nutrientes, responsáveis pela maior intensidade da cercosporiose (Siddiqi, 1970; Fernandez-Borrero \& Lopez-Duque, 1971; Chalfoun, 1997; Carvalho \& Chalfoun, 1998; Mansk, 1990). Os dados também consolidam os resultados de Echandi (1959), mostrando menor incidência da cercosporiose em plantas de café irrigadas em relação às desprovidas de irrigação. A falta de umidade no solo pode condicionar a planta à menor absorção de nutrientes, tornando-a suscetível à infecção de C. coffeicola.

A função do gotejamento na fertirrigação é enviar água e nutrientes diretamente às raízes da planta; portanto, não promove o molhamento foliar. Esse sistema também pode trazer maiores benefícios às plantas, tornando-as mais vigorosas e resistentes ao patógeno. Segundo Rotem \& Palti (1969), para doenças foliares, o efeito da umidade do solo limita-se ao hospedeiro por 
meio de crescimentos periódicos suscetíveis a certas doenças e efeito na turgidez da folha. De acordo com os mesmos autores, a maior turgidez da folha tornou plantas de banana e de feijão suscetíveis a Cercospora musae e Colletotrichum lindemuthianum, respectivamente. A alta turgidez da folha promoveria a abertura dos estômatos e assim facilitaria a penetração dos patógenos. Apesar de C. coffeicola penetrar na folha através dos estômatos (Echandi, 1959; Siddiqi, 1970), no presente trabalho, a possível turgidez das folhas de café, pelo fato de as plantas receberem água via irrigação, não alterou a suscetibilidade das plantas a esse patógeno.

A análise das curvas de progresso da doença mostrou maior incidência nos meses de maio e junho na testemunha, com manejo convencional não irrigado. A testemunha adubada 4 vezes e não irrigada apresentou pontos de máxima incidência por volta dos meses de maio a julho (Figura 2).

Ocorreu aumento gradativo na precipitação pluviométrica e na temperatura por volta do mês de outubro, juntamente com o início do calendário das adubações, condições pouco favoráveis ao progresso da doença (Zambolim et al., 1997). Segundo as curvas de progresso da doença nos diferentes parcelamentos de adubação, pontos de máxima incidência ocorreram por volta dos meses de maio a setembro (Figura 1- A, $\mathrm{B}, \mathrm{D})$.

No teste de correlação da incidência da cercosporiose com as variáveis climáticas (Tabela 5), observou-se correlação negativa entre as temperaturas e todos os tratamentos, com exceção do parcelamento em 36 vezes com a temperatura máxima, o qual não foi significativo.
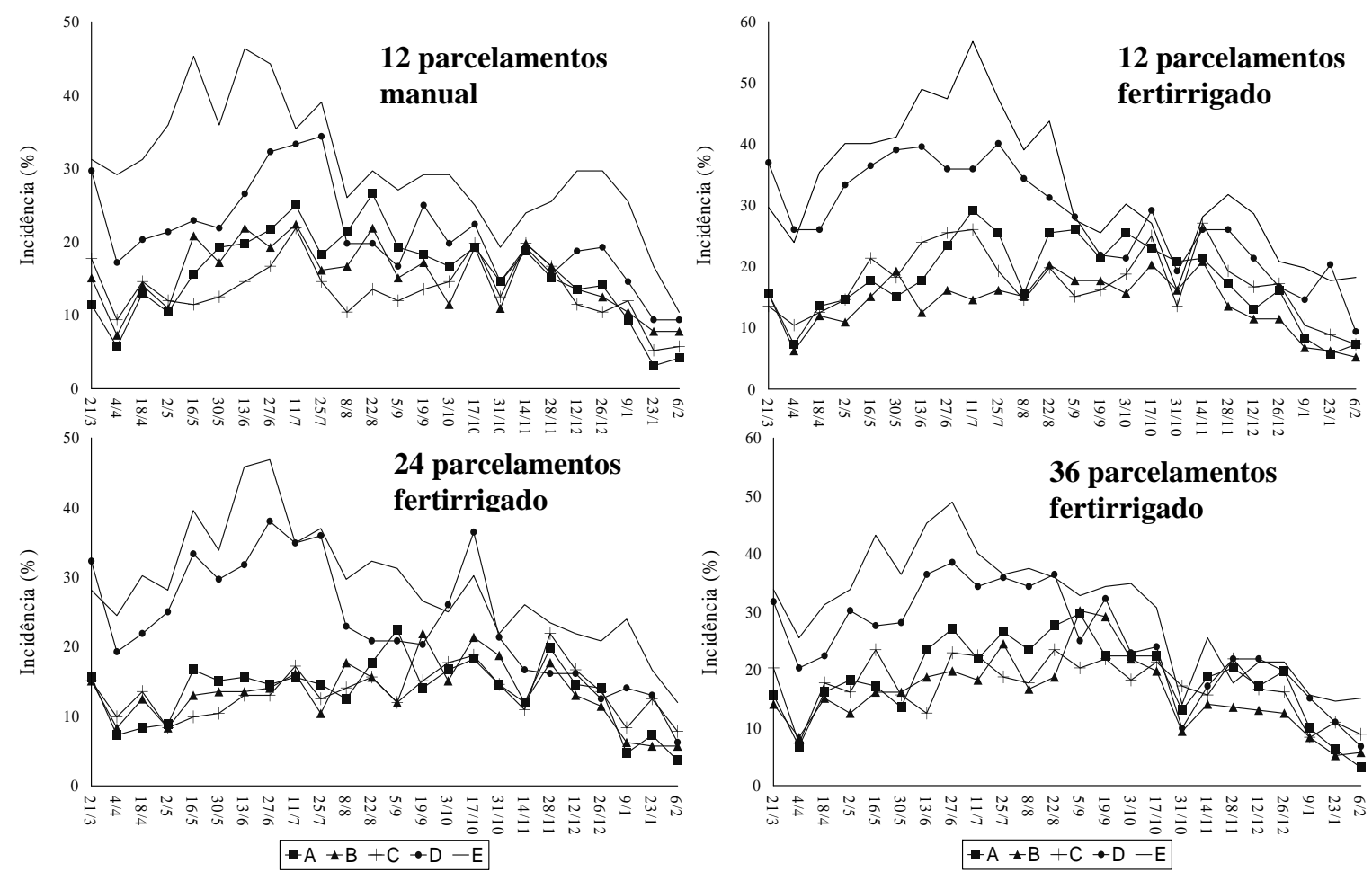

FIGURA 2 - Curvas de progresso da cercosporiose do cafeeiro em diferentes parcelamentos de adubação e diferentes épocas de início de irrigação (subparcelas A: $1^{\circ}$ de junho, B: 15 de julho, C: $1^{\circ}$ de setembro) e testemunhas (D: tratamento adicional 1- fertirrigação parcelada em 4 vezes e não irrigado; E: tratamento adicional 2- adubação convencional, não irrigado). 
TABELA 5 - Teste de correlação dos dados climáticos de temperatura máxima, mínima e média, precipitação e umidade relativa do ar com a incidência da cercosporiose nos diferentes parcelamentos de adubação.

\begin{tabular}{lccccc}
\hline $\begin{array}{c}\text { Número } \\
\text { parcelamentos }\end{array}$ & $\begin{array}{c}\text { Temperatura } \\
\text { máxima }\left({ }^{\circ} \mathbf{C}\right)\end{array}$ & $\begin{array}{c}\text { Temperatura } \\
\text { mínima }\left({ }^{\circ} \mathbf{C}\right)\end{array}$ & $\begin{array}{c}\text { Temperatura } \\
\text { média }\left({ }^{\circ} \mathbf{C}\right)\end{array}$ & $\begin{array}{c}\text { Precipitação } \\
(\mathbf{m m})\end{array}$ & $\begin{array}{c}\text { Umidade Rela- } \\
\text { tiva }(\%)\end{array}$ \\
\hline 12 (manual) & $-0,55^{* *}$ & $-0,75^{* *}$ & $-0,71^{* *}$ & $-0,47 *$ & $-0,48^{*}$ \\
12 (fertirrigado) & $-0,58^{* *}$ & $-0,81^{* *}$ & $-0,75^{* *}$ & $-0,52^{* *}$ & $-0,55^{* *}$ \\
24 (fertirrigado) & $-0,46^{*}$ & $-0,70^{* *}$ & $-0,63^{* *}$ & $-0,43 \mathrm{NS}$ & $-0,52^{* *}$ \\
36 (fertirrigado) & $-0,36 \mathrm{NS}$ & $-0,73^{* *}$ & $-0,61 * *$ & $-0,64 * *$ & $-0,68^{* *}$ \\
\hline
\end{tabular}

* Significativo $\mathbf{P}(<0,05)$

** Significativo $\mathbf{P}(<\mathbf{0 , 0 1})$

NS- Não-significativo

Entre a precipitação e a incidência da doença, não houve correlação significativa no tratamento com 24 parcelamentos. Nos parcelamentos restantes, houve correlação negativa; portanto, maiores precipitações levaram à menor incidência da doença. Houve correlação negativa entre a incidência da doença e a umidade relativa do ar. Esse resultado também pode ser visualisado no gráfico das precipitações em comparação com o gráfico da incidência da doença (Figura 1- A, B, D). Períodos de estiagem prolongada, sem o uso da irrigação, favorecem a incidência da doença pelo fato de as plantas tornarem-se deficientes em nutrientes (Zambolim et al., 1985; 1997).

\section{REFERÊNCIAS BIBLIOGRÁFICAS}

AKUTSU, M. Relações de funções climáticas e bióticas com a taxa de infecção da ferrugem do cafeeiro (Hemileia vastatrix). 1981. 67 p. Tese (Mestrado em Fitopatologia) - Universidade de Viçosa, Viçosa.

ALEXANDRE-POZZA, A. A. Influência da nutrição nitrogenada e potássica na intensidade da mancha de olho pardo (Cercospora coffeicola) em mudas de cafeeiro. 1999.70 p. Dissertação (Mestrado em Fitotecnia) - Universidade de Viçosa, Viçosa.

CAMPBELL, C. L.; MADDEN, L. V. Introduction to plant disease epidemiology. New york: J. Wiley, 1990. $532 \mathrm{p}$.

CARVAlHO, A. M. C. Progresso da ferrugem (Hemileia vastatrix) em diferentes sistemas de irrigação. 32 p. 1998. Monografia (Para obtenção do Título de Engenheiro Agrônomo) - Universidade de Uberlândia, Uberlândia.
CARVALHO, V. L. de. Influência de níveis de produção sobre a evolução da ferrugem e a composição química das folhas do cafeeiro. 1991. 85 p. Dissertação (Mestrado em Fitossanidade) - Universidade Federal de Lavras, Lavras.

CARVAlHO, V. L. de; CHALFOUN, S. M. Manejo integrado das principais doenças do cafeeiro. Informe Agropecuário, Belo Horizonte, v. 19, n. 193, p. 27-35, 1998.

CHALFOUN, S. M. Doenças do cafeeiro: importância, identificação e métodos de controle. Lavras: UFLA/FAEPE, 1997. 96 p.

CHALFOUN, S. M.; ZAMBOLIM, L. Ferrugem do cafeeiro. Informe Agropecuário, Belo Horizonte, v. 11, n. 126 , p. 42-46, jun. 1985 .

ECHANDI, E. La chasparria de los cafetos causada por el hongo Cercospora coffeicola Berk \& Cooke. Turrialba, Costa Rica, v. 9, n. 2, p. 54-67, abr./jun. 1959.

FERNANDEZ-BORRERO, O.; LOPEZ-DUQUE, S. Fertilizacion de plantulas de café e su relacion com la incidencia de la mancha de hierro (Cercospora coffeicola, Berk \& Cooke). Cenicafé, Caldas, v. 22, n. 4, p. 95108, out. 1971 .

GODOY, C. V., BERGAMIN FILHO, A.; SALGADO, C. L. Doenças do cafeeiro (Coffea arabica L.). In: KIMATI, H. Manual de fitopatologia: doenças de plantas e seu controle. 3. ed. São Paulo: Agronômica Ceres, 1997. v. 2, p. 184-200. 
KUSHALAPPA, A. C.; CHAVES, G. M. An analysis of the development of coffee rust in the field. Fitopatologia Brasileira, Brasília, v. 5, n. 1, p. 95-113, fev. 1980.

MANSK, Z. Doenças do cafeeiro. In: CONGRESSO BRASILEIRO DE PESQUISAS CAFEEIRAS, 16., 1990, Espírito Santo do Pinhal. Resumos... Rio de Janeiro: Faculdade de Agronomia e Zootecnia, 1990. p. 61-77.

ROTEM, J.; PALTI, J. Irrigation and plant diseases. Annual Review of Phytopathology, Palo Alto, v. 7, p. 267-288, 1969.

RIBEIRO DO VALE, F. X.; ZAMBOLIM, L. Influência da temperatura e da umidade nas epidemias de doenças de plantas. Revisão Anual de patologia de plantas, Passo Fundo, v. 4, p. 149-207, 1996.

SANTOS, F. A. S.; MATIELLO, J. B., RIBEIRO, R. W. C.; SANTINATO, R. Épocas de controle da cercosporiose (Cercospora coffeicola) no estado de Pernambuco - Garanhuns. In: CONGRESSO BRASILEIRO DE PESQUISAS CAFEEIRAS, 12., 1985, Caxambu. Resumos... Rio de Janeiro: IBC, 1985. p. $182-183$.
SIDDIQI, M. A. Incidence, development and symptoms of Cercospora disease of coffee in Malawi. Transactions British Mycological Society, London, v. 54, n. 3, p. 415-421, 1970.

SILVA-ACUÑA, R.; ZAMBOLIM, L.; CRUZ, C. D.; VALE, F. X. R. Estudo epidemiológico da ferrugem do cafeeiro (Hemileia vastatrix) utilizando a análise de trilha. Fitopatologia Brasileira, Brasília, v. 23, n. 4, p. 425-430, dez. 1998.

SOUZA, S. M. C. Importância da chuva e da temperatura do ar na incidência da ferrugem (Hemileia vastatrix Berk. \& Br.) em cafeeiros, de três localidades do estado de Minas Gerais. 1980. 50 p. Dissertação (Mestrado em Fitotecnia) - Universidade de Lavras, Lavras.

ZAMBOLIM, L.; MARTINS, M. C. del P.; CHAVES, G. M. Café. Informe Agropecuário, Belo Horizonte, v. 11, n. 131, p. 64-75, nov. 1985.

ZAMBOLIM, L.; RIBEIRO DO VALE, F. X.; PEREIRA, A. A.; CHAVES, G. M. Café (Coffea arabica L.), controle de doenças. In: RIBEIRO DO VALE, F. X.; ZAMBOLIM, L. Controle de doenças de plantas: grandes culturas. Viçosa: Departamento de Fitopatologia, 1997. v. 2, p. 83-179. 